\title{
Development of bioelectrical impedance analysis-based equations for estimation of body composition in postpartum rural Bangladeshi women
}

\author{
Saijuddin Shaikh ${ }^{1}$, Kerry J. Schulze ${ }^{2 *}$, Anura Kurpad ${ }^{3}$, Hasmot Ali $^{1}$, Abu Ahmed Shamim ${ }^{1}$, \\ Sucheta Mehra ${ }^{2}$, Lee S.-F. Wu ${ }^{2}$, Mahbubar Rashid ${ }^{1}$, Alain B. Labrique ${ }^{2}$, Parul Christian ${ }^{2}$ and \\ Keith P. West $\mathrm{Jr}^{2}$ \\ ${ }^{1}$ The JiVitA Project, Chalkmamrojpur, Shadullapur Road, Gaibandha, Bangladesh \\ ${ }^{2}$ Department of International Health, Center for Human Nutrition, Johns Hopkins Bloomberg School of Public Health, 615 \\ North Wolfe Street, Room W2041, Baltimore, MD 21205, USA \\ ${ }^{3}$ Saint John's Research Institute, Saint John's Medical College, Saint John's National Academy of Health Sciences, Bangalore \\ 560 034, India
}

(Submitted 11 October 2011 - Final revision received 9 March 2012 - Accepted 12 March 2012 - First published online 4 May 2012)

\begin{abstract}
Equations for predicting body composition from bioelectrical impedance analysis (BIA) parameters are age-, sex- and population-specific. Currently there are no equations applicable to women of reproductive age in rural South Asia. Hence, we developed equations for estimating total body water (TBW), fat-free mass (FFM) and fat mass in rural Bangladeshi women using BIA, with ${ }^{2} \mathrm{H}_{2} \mathrm{O}$ dilution as the criterion method. Women of reproductive age, participating in a community-based placebo-controlled trial of vitamin A or $\beta$-carotene supplementation, were enrolled at $19 \cdot 7$ (SD 9.3) weeks postpartum in a study to measure body composition by ${ }^{2} \mathrm{H}_{2} \mathrm{O}$ dilution and impedance at $50 \mathrm{kHz}$ using multi-frequency BIA ( $n$ 147), and resistance at $50 \mathrm{kHz}$ using single-frequency BIA ( $n$ 82). TBW $(\mathrm{kg})$ by ${ }^{2} \mathrm{H}_{2} \mathrm{O}$ dilution was used to derive prediction equations for body composition from BIA measures. The prediction equation was applied to resistance measures obtained at 13 weeks postpartum in a larger population of postpartum women ( $n$ 1020). TBW, FFM and fat were $22 \cdot 6$ (SD $2 \cdot 7$ ), $30 \cdot 9$ (SD 3.7) and 10.2 (SD 3.8) $\mathrm{kg}$ by ${ }^{2} \mathrm{H}_{2} \mathrm{O}$ dilution. Height ${ }^{2} /$ impedance or height ${ }^{2} /$ resistance and weight provided the best estimate of TBW, with adjusted $R^{2} 0.78$ and 0.76 , and with paired absolute differences in TBW of $0.02(\mathrm{SD} 1.33$ ) and 0.00 (SD 1.28$) \mathrm{kg}$, respectively, between BIA and ${ }^{2} \mathrm{H}_{2} \mathrm{O}$. In the larger sample, values for TBW, FFM and fat were $23.8,32.5$ and $10.3 \mathrm{~kg}$, respectively. BIA can be an important tool for assessing body composition in women of reproductive age in rural South Asia where poor maternal nutrition is common.
\end{abstract}

Key words: Body composition: Total body water: Bioelectrical impedance analysis: ${ }^{2} \mathbf{H}_{2} \mathrm{O}$ dilution: Prediction equations: Women: Reproductive age: South Asia

Poor maternal nutritional status may be one reason for high rates of infant low birth weight in South Asian countries ${ }^{(1)}$, where women of reproductive age are likely to suffer from macro- and micronutrient deficiencies ${ }^{(2,3)}$. Low BMI at the onset of pregnancy has been associated with adverse birth outcomes in a variety of settings ${ }^{(4)}$, but more specifically birth weight has been positively associated with maternal fat-free mass (FFM) content measured following pregnancy in Indian $^{(5)}$ and Mexican ${ }^{(6)}$ mothers. Conversely, excess body fat has been linked to increasing rates of metabolic syndrome and cardiovascular risk, now observed even in rural populations of South $\mathrm{Asia}^{(7)}$. Because specific components of body composition appear to be linked to two of the major public health problems of South Asia, adequately characterising body composition in populations in this region of the world is critical.

Body composition in field settings is often assessed using weight, height, circumference, or skinfolds as proxies for direct measures of fat and lean mass components. Using weight, height or BMI $\left(\mathrm{kg} / \mathrm{m}^{2}\right)$ alone will not distinguish fat and FFM compartments, which play different metabolic roles. Moreover, there is evidence that individuals of Asian descent have more body fat for a given BMI than Caucasian populations ${ }^{(8-10)}$. Skinfolds may provide regional information on fat depots and can be used to estimate whole-body composition, and waist circumference reflects central fat deposition.

Abbreviations: BIA, bioelectrical impedance analysis; FFM, fat-free mass; MF-BIA, multi-frequency bioelectrical impedance analysis; $R_{50}$, resistance at $50 \mathrm{kHz}$; RMSE, root mean square error; SF-BIA, single-frequency bioelectrical impedance analysis; TBW, total body water; $Z_{50}$, impedance at $50 \mathrm{kHz}$ 
However, more sophisticated body composition methods are not readily applicable in field settings on a large scale (e.g. ${ }^{2} \mathrm{H}_{2} \mathrm{O}$ dilution) or are completely laboratory or clinicbased (dual energy X-ray absorptiometry, air displacement plethysmography, etc).

Bioelectrical impedance analysis (BIA), in contrast, provides a potentially field-applicable means for assessing body composition in large, community-based epidemiological studies. It is safe, easy to use, non-invasive, portable and inexpensive. In single-frequency BIA (SF-BIA), a single current, typically $50 \mathrm{kHz}$, is applied to the body. The resistance of the body to the current is inversely proportional to the amount of body water and, thus, FFM content. Additionally, with multifrequency BIA (MF-BIA), a current at several frequencies is applied that allows for the distinction between inter- and intra-cellular fluid ${ }^{(11)}$.

Numerous studies have reported that BIA reliably predicts total body water (TBW) or FFM, and a variety of equations to estimate these outcomes from BIA have been established, as summarised elsewhere ${ }^{(11)}$. However, to ensure the validity of such prediction equations, they should be derived under population-specific (e.g. sex, age and ethnicity) conditions by comparing bioelectrical impedance measures to more direct measures of TBW or FFM. Relatively few studies ${ }^{(12-16)}$ have been conducted to establish body composition equations from BIA in Asian populations. Furthermore, these equations are probably not applicable to rural South Asian women with poor nutritional status, whose body size is considerably different from that of women reported elsewhere ${ }^{(17)}$.

In the present study, we developed an equation to predict TBW from BIA measures in postpartum women in rural Bangladesh, using ${ }^{2} \mathrm{H}_{2} \mathrm{O}$ dilution as the criterion method. We then applied this equation to a larger population of postpartum women in the same community to demonstrate its utility for determining body composition in this population.

\section{Experimental methods}

\section{Study subjects}

The present study was conducted within a large, randomised, community-based trial to evaluate the impact of vitamin A and $\beta$-carotene supplementation on all-cause, pregnancy-related maternal and infant mortality ${ }^{(18)}$. The trial was conducted in ninety unions in the District of Gaibandha in northwestern Bangladesh from August 2001 to February 2007. Details of the main trial and its more intensive substudy have been provided elsewhere ${ }^{(18,19)}$. Briefly, of 596 individual 'sectors', small geographical regions that functioned as randomisation units, thirty-two contiguous sectors were designated for enhanced, home-based biochemical and anthropometric assessments that occurred shortly following pregnancy ascertainment (early pregnancy), in late pregnancy, and at approximately 3 months following the end of pregnancy, i.e. after a birth or after pregnancy termination due to abortion, miscarriage or stillbirth. These assessments were carried out by five specially trained teams and included anthropometry and SF-BIA. Postpartum data were collected on women from the main study from June 2003 until March 2007. Weight of the women was measured with a scale accurate to $0.2 \mathrm{~kg}$ (SECA Electronic Scale 890; UNICEF). Height was measured using a stadiometer to the nearest $0 \cdot 1 \mathrm{~cm}$, and skinfolds and midupper arm circumference were measured using standardised techniques. A single-frequency, portable bioelectrical body composition analyser (Quantum II; RJL Systems) at $50 \mathrm{kHz}$ was used to obtain resistance and reactance measurements from women as they lay supine on a non-conducting surface, as described previously ${ }^{(17)}$.

Beginning in the autumn of 2005 , the postpartum visit also served as an opportunity to recruit women for a more intensive body composition study, which took place from spring of 2006 to early 2007. A subset of lactating women at the 3-month postpartum visit, selected in part based on their proximity to main roads to facilitate bringing them to a central location, was invited to participate in a clinic-based study to develop body composition equations for resistance (using SF-BIA; RJL Systems) or impedance (using MF-BIA, Quadscan 2000; BodyStat Limited). The purpose of this study was to generate equations to predict TBW (kg), using ${ }^{2} \mathrm{H}_{2} \mathrm{O}$ dilution as the referent method, as will be described next. Further, the prediction equation for TBW was applied to the larger population of postpartum women in the community with successful pregnancy outcomes (i.e. living infant) and valid resistance measures at 3 months postpartum to examine body composition in the larger population.

The study was conducted according to the guidelines laid down in the Declaration of Helsinki and all procedures involving human subjects were approved by the Johns Hopkins Bloomberg School of Public Health Institutional Review Board in the USA and the Bangladesh Medical Research Council in Bangladesh. Verbal consent was obtained from all participants. Consent was witnessed and formally recorded.

\section{Body composition study procedures}

Women who consented to participate in the body composition study were brought in groups of five to eight, with their infants and a family member, to a central facility by vehicle in the morning after an overnight fast. A uniform breakfast was served upon arrival. A pre-weighed sari (median weight $300 \mathrm{~g}$ ) was provided to each woman in order to measure body weight with uniform clothing. Before the initiation of any procedures, women were asked to breastfeed their infants and to void urine. Weight was measured to the nearest $0.2 \mathrm{~kg}$ (SECA Electronic Scale 890; UNICEF), and height was measured to the nearest $0.1 \mathrm{~cm}$ using a locally made fixed stadiometer modified with a level affixed to the cross-bar to help position subjects along the Frankfort plane. Baseline saliva samples were collected using sterile cotton cylinders (Salivette tubes; Sarstedt AG and Company) $2 \mathrm{~h}$ following breakfast to determine the natural ${ }^{2} \mathrm{H}$ enrichment for each participating woman. Doses of enriched ${ }^{2} \mathrm{H}_{2} \mathrm{O}$ (99.8\% reported ${ }^{2} \mathrm{H}$ enrichment; Cambridge Isotope Laboratories, Inc.) had been prepared the night before the study for each woman based on her body weight obtained during the home visit. A $0 \cdot 15 \mathrm{~g} / \mathrm{kg}$ body weight dose $^{(20)}$ was sealed in an individually labelled plastic cup. 
Individually labelled doses of ${ }^{2} \mathrm{H}_{2} \mathrm{O}$ were carefully administered to each woman, with the exact dose consumed calculated by difference in the weight of the dose cup and its cap before and after dosing. Following dosing, $75 \mathrm{ml}$ of water was provided as a rinse to ensure that the total dose was swallowed. Follow-up saliva samples were collected $3 \mathrm{~h}$ after dose administration. During the $3 \mathrm{~h}$ equilibration period, women were not allowed to consume food or liquid and were requested to allow us to take their infants' weight before and after breast-feeding and measure the volume of any urine voided to account for any loss of body fluids.

During the isotope equilibration period, MF-BIA was measured in all women, while SF-BIA was also measured in a subset of women at the same visit to allow us to apply prediction equations to resistance data already collected in the field. When both MF- and SF-measurements were taken, they were done so one after the other so that the study conditions were identical. Using the MF-BIA instrument and $2 \times 7 \mathrm{~cm}$ electrodes recommended by the manufacturer, impedance $(Z)$ was recorded at 5, 50, 100 and $200 \mathrm{kHz}$. Resistance and reactance in Ohms $(\Omega)$ at $50 \mathrm{kHz}$ were assessed for SF-BIA using $1 \times 4 \mathrm{~cm}$ electrodes provided by the manufacturer. Analysers were tested in the morning on each day of use with standard resistors at $500 \Omega$ supplied by the manufacturers, with acceptable limits of 496-503 $\Omega$ for the MF-BIA unit and 495-505 $\Omega$ for the SF-BIA unit. Only resistance $\left(R_{50}\right)$ from SF-BIA and impedance at $50 \mathrm{kHz}\left(Z_{50}\right)$ from MF-BIA were used for developing body composition prediction equations.

\section{Laboratory analysis of saliva and dose ${ }^{2} \mathrm{H}_{2}$ enrichment}

Cotton cylinders saturated with saliva were centrifuged for $5 \mathrm{~min}$ at $6000 \mathrm{rpm}$ to precipitate saliva, which was kept at $-20^{\circ} \mathrm{C}$ until analysis. Baseline and post-equilibration saliva samples, along with an aliquot of ${ }^{2} \mathrm{H}_{2} \mathrm{O}$ from each of two bottles of ${ }^{2} \mathrm{H}_{2} \mathrm{O}$ stock from which the doses were prepared, were transported to Saint John's Research Institute, Bangalore, India for the analysis of ${ }^{2} \mathrm{H}$ enrichment by $\mathrm{Zn}$ reduction followed by dual-inlet MS (Europa Scientific) ${ }^{(21)}$. Each sample was analysed in duplicate and the mean was used for analysis. Repeated analysis for natural background samples gave a CV of $0.02 \%$.

\section{Body composition calculations}

TBW (kg) was calculated using data on dose enrichment and weight and the change in the enrichment of ${ }^{2} \mathrm{H}$ in maternal saliva over the equilibration period, using the molar weight of ${ }^{2} \mathrm{H}_{2} \mathrm{O}$ of $20.0274 \mathrm{~g} / \mathrm{mol}$ and of pure water of $18.0153 \mathrm{~g} / \mathrm{mol}^{(22)}$, and accounting for $4 \%$ hydrogen exchange ${ }^{(21)}$. After determining TBW either via ${ }^{2} \mathrm{H}_{2} \mathrm{O}$ dilution or from BIA prediction equations, FFM ( $\mathrm{kg}$ ) was determined assuming hydration of FFM was $0.732^{(23,24)}$. Fat mass $(\mathrm{kg})$ was determined as the difference between total body weight (kg) and FFM (kg). All these body composition components were also expressed as a percentage of total body weight.

\section{Statistical analysis}

Differences in subject characteristics between the women selected for body composition assessment and those of the larger population of women with a living infant from a singleton birth, complete data for weight, height and resistance, and a valid resistance measure of $>400 \Omega$ were examined by $t$ test or $\chi^{2}$ analysis, with differences considered significant at $P<0.05$. Within the body composition group, differences in women who had only impedance measured $v$. those with both impedance and resistance were also examined by $t$ test. Comparability of impedance and resistance among women with both measurements was examined by correlation analysis and paired $t$ test.

We used TBW (kg) derived from ${ }^{2} \mathrm{H}_{2} \mathrm{O}$ dilution as the dependent variable to develop regression equations to predict TBW from resistance or impedance using forward stepwise regression, with height ${ }^{2} / Z_{50}$ or height ${ }^{2} / R_{50}$, weight and age as predictor variables. Other anthropometric variables were also initially examined. For comparing the models, we sought the highest adjusted $R^{2}$ values, and lowest root mean square error (RMSE), a measure of precision ${ }^{(25)}$. The precision and robustness of the prediction equations were also assessed by calculating the PRESS statistic as part of an internal crossvalidation strategy ${ }^{(25,26)}$. The PRESS statistic is calculated as the square root of the sum of the squared prediction residuals divided by the total number of observations, with a lower PRESS statistic indicative of better fit of the prediction equation. The prediction residuals were obtained by fitting the regression equations with actual TBW as the dependent variable and height ${ }^{2} / Z_{50}$ (or $R_{50}$ ) and weight as independent variables for all but one observation sequentially, obtaining the predicted value of the excluded observation, and calculating the prediction residual as the observed - predicted value for $\mathrm{TBW}^{(25,26)}$. Scatterplots of predicted $v$. actual measures of TBW and the predicted residuals against predicted TBW were generated.

The equation for TBW from resistance measures was applied to the larger population from whom the body composition study women were derived, and body composition data were explored in relation to age and BMI category by ANOVA.

Statistical analyses were performed using STATA version 10 (Stata Corporation), although the PRESS residuals and statistic were obtained using the PROC REG procedure with PRESS Statistics in SAS version 9.2 (SAS Institute, Inc.).

\section{Results}

A total of 147 women successfully completed the body composition assessments, of which eighty-two had both resistance and impedance measures taken. Data for one woman had been dropped due to implausibly high TBW assessed by ${ }^{2} \mathrm{H}_{2} \mathrm{O}$ dilution. The larger sample of women in the main trial substudy ( $n$ 1020) was similar to the women in the body composition study in that they also had a living infant and complete and valid data for weight, height and resistance at the time of the 3-month postpartum home visit. Data from the 3-month postpartum home visit comparing the women in 
Table 1. Characteristics of postpartum women participating in the body composition study at the time of enrolment in early pregnancy and their comparability to the larger group of women

(Mean values and standard deviations)

\begin{tabular}{|c|c|c|c|c|c|}
\hline & \multicolumn{2}{|c|}{$\begin{array}{c}\text { Body } \\
\text { composition } \\
\text { study }(n 147)\end{array}$} & \multicolumn{2}{|c|}{$\begin{array}{l}\text { Non-body } \\
\text { composition } \\
\text { study } \\
(n 1020)\end{array}$} & \multirow[b]{2}{*}{$P$} \\
\hline & Mean & SD & Mean & SD & \\
\hline $\begin{array}{l}\text { Time postpartum } \\
\text { (weeks) }\end{array}$ & $13 \cdot 3$ & $2 \cdot 0$ & $13 \cdot 1$ & $2 \cdot 1$ & 0.230 \\
\hline Age (years) & $20 \cdot 8$ & $5 \cdot 3$ & $22 \cdot 6$ & $5 \cdot 6$ & 0.0004 \\
\hline Weight (kg) & $41 \cdot 7$ & $6 \cdot 1$ & $42 \cdot 8$ & 5.5 & 0.02 \\
\hline Height $(\mathrm{cm})$ & 148.4 & $5 \cdot 1$ & 149.1 & $5 \cdot 2$ & $0 \cdot 10$ \\
\hline BMI $\left(\mathrm{kg} / \mathrm{m}^{2}\right)$ & 18.9 & $2 \cdot 1$ & $19 \cdot 2$ & $2 \cdot 0$ & 0.06 \\
\hline MUAC (cm) & $22 \cdot 2$ & $2 \cdot 0$ & $22 \cdot 6$ & $2 \cdot 0$ & 0.04 \\
\hline Triceps skinfold (mm) & $9 \cdot 7$ & $3 \cdot 3$ & $10 \cdot 5$ & 3.7 & 0.01 \\
\hline $\begin{array}{l}\text { Subscapular } \\
\text { skinfold (mm) }\end{array}$ & $12 \cdot 2$ & 4.4 & $13 \cdot 8$ & 4.8 & $<0.0001$ \\
\hline$R_{50}(\Omega)$ & 729 & 71 & 694 & 79 & $<0.0001$ \\
\hline
\end{tabular}

MUAC, mid-upper arm circumference; $R_{50}$, resistance at $50 \mathrm{kHz}$.

the ${ }^{2} \mathrm{H}_{2} \mathrm{O}$ dilution study and the larger sample are shown in Table 1 . Women participating in the body composition study were significantly younger, weighed less, had lower skinfold and mid-upper arm circumference measures and had higher resistance values at 3 months postpartum. Additionally, body composition study participants were more likely to be primiparous (66 v. 45\%; $P<0.0001$ ). Despite these differences, both groups revealed women of reproductive age with high rates of underweight and short stature.

The subgroup of eighty-two women in the body composition study who had the resistance measure was similar in most characteristics to the larger group of 147 (Table 2), although they had somewhat higher impedance values than the sixty-five women who had data for impedance values alone $(P=0.01)$. Median length of time between the home visit and the body composition assessment was 1.9 weeks among all women.

\section{Prediction equation}

TBW (kg) by ${ }^{2} \mathrm{H}_{2} \mathrm{O}$ dilution was 22.6 (SD 2.7 ) $\mathrm{kg}$ among the 147 body composition study women, and 22.6 (SD $2 \cdot 8$ ) $\mathrm{kg}$ among the subset of eighty-two women. Although 141 (96\%) women breastfed their infants one to three times during the ${ }^{2} \mathrm{H}_{2} \mathrm{O}$ equilibration period, the contribution of the loss of fluid as breast milk to calculations of TBW was negligible (median weight of breast milk $70 \mathrm{~g}$ ). Only six (4\%) women voided urine during the equilibration period, also in amounts negligible to the calculation of TBW (median weight of urine, $180 \mathrm{~g}$ ).

Impedance measures using the MF-BIA instrument and resistance measures using the SF-BIA instrument in the same eighty-two women were highly correlated with $r 0.985$, $(P<0.0001)$ for raw values, and $r 0.993 \quad(P<0.0001)$ for height ${ }^{2} / Z_{50}$ and height ${ }^{2} / R_{50}$. The within-woman difference in these measures, while statistically significant $(P<0 \cdot 0001)$, was minimal ( -14.3 (SD 12.7) for impedance-resistance; 0.57 (SD 0.49) when expressed as the denominator of height ${ }^{2}$ ) relative to a range of $580-998 \Omega$ for $Z_{50}$ and $R_{50}$ and $20-44 \mathrm{~cm}^{2} / \Omega$ for height ${ }^{2} / Z_{50}$ and height ${ }^{2} / R_{50}$, respectively, observed in these women. Thus, coefficients for the prediction equation for TBW were similar whether using impedance or resistance. Regression parameters for the stepwise prediction equation development process are shown in Table 3 for impedance and resistance measures, as variables were added into the prediction equations. Age did not contribute significantly in the prediction of TBW and was therefore ultimately excluded from both models. The final equations were

$$
\begin{aligned}
\text { Impedance based: TBW }= & 4.573+0.177 \times W \\
& +0.351 \times \mathrm{Ht}^{2} / Z_{50}, \\
\text { Resistance based: TBW }= & 4.297+0.190 \times W \\
+ & 0.349 \times \mathrm{Ht}^{2} / R_{50},
\end{aligned}
$$

where TBW is in $\mathrm{kg}$; $\mathrm{Ht}$, height in $\mathrm{cm}$; $W$, weight in $\mathrm{kg}$. The total variance in TBW that was explained by the prediction models was 76 and $78 \%$ using impedance and resistance, respectively. Body weight explained 65 and $68 \%$ of the variance in TBW when it alone was in the models (not shown) and weight was highly correlated with $\mathrm{Ht}^{2} / Z_{50}(r \quad 0.76)$ and $\mathrm{Ht}^{2} / R_{50}(r \quad 0 \cdot 77)$, both $P<0 \cdot 0001$. The RMSE for TBW for the final equations were 1.34 and $1.30 \mathrm{~kg}$, respectively (Table 3 ).

\section{Application of bioelectrical impedance analysis equations}

Mean TBW, FFM and fat mass obtained using the final developed equations and those obtained by ${ }^{2} \mathrm{H}_{2} \mathrm{O}$ dilution are shown in Table 4. Predicted TBW using the equation for $Z_{50}$ was 0.02 (SD 1.33) kg higher than actual TBW, and predicted TBW using $R_{50}$ differed by 0.00 (SD 1.28 ) kg from actual TBW, both near zero and neither different by paired $t$ test.

Table 2. Anthropometric and bioelectrical impedance characteristics of

\begin{tabular}{|c|c|c|c|c|}
\hline & \multicolumn{2}{|c|}{$\begin{array}{c}\text { Body } \\
\text { composition study } \\
\text { participants } \\
(n 147)\end{array}$} & \multicolumn{2}{|c|}{$\begin{array}{c}\text { Resistance } \\
\text { measurement } \\
\text { subgroup ( } n 82)\end{array}$} \\
\hline & Mean & SD & Mean & SD \\
\hline $\begin{array}{l}\text { Time postpartum } \\
\text { (weeks) }\end{array}$ & $19 \cdot 7$ & $9 \cdot 3$ & $15 \cdot 2$ & $2 \cdot 6$ \\
\hline Weight $(\mathrm{kg})$ & $41 \cdot 1$ & $6 \cdot 1$ & $41 \cdot 7$ & $6 \cdot 2$ \\
\hline Height $(\mathrm{cm})$ & 148.7 & $5 \cdot 2$ & 148.9 & 5.7 \\
\hline BMI (kg/m²) & 18.5 & $2 \cdot 1$ & $18 \cdot 7$ & $2 \cdot 1$ \\
\hline$Z_{50}(\Omega)$ & 729 & 75 & 743 & 73 \\
\hline Height $^{2} / Z_{50}\left(\mathrm{~cm}^{2} / \Omega\right)$ & $30 \cdot 7$ & $4 \cdot 1$ & $30 \cdot 2$ & $4 \cdot 2$ \\
\hline$R_{50}(\Omega)$ & - & - & 757 & 74 \\
\hline Height $^{2} / R_{50}\left(\mathrm{~cm}^{2} / \Omega\right)$ & - & - & $29 \cdot 7$ & $4 \cdot 2$ \\
\hline
\end{tabular}
all women in the body composition study, and in the subgroup in whom resistance was measured

(Mean values and standard deviations)

$Z_{50}$, impedance at $50 \mathrm{kHz} ; R_{50}$, resistance at $50 \mathrm{kHz}$. 


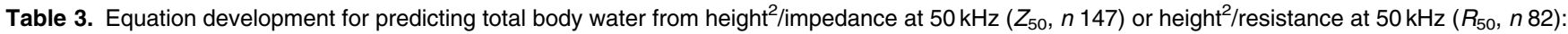
regression parameters

( $\beta$ Coefficients and $95 \%$ confidence intervals)

\begin{tabular}{|c|c|c|c|c|c|c|c|c|c|c|}
\hline & \multicolumn{2}{|c|}{ Height $^{2} / Z_{50}\left(\mathrm{~cm}^{2} / \Omega\right)$} & \multicolumn{2}{|c|}{ Weight (kg) } & \multicolumn{2}{|c|}{ Age (years) } & \multicolumn{2}{|c|}{ Intercept (kg) } & \multirow[b]{2}{*}{$\operatorname{Adj} R^{2}$} & \multirow[b]{2}{*}{ RMSE } \\
\hline & $\beta$ & $95 \% \mathrm{Cl}$ & $\beta$ & $95 \% \mathrm{Cl}$ & $\beta$ & $95 \% \mathrm{Cl}$ & $\beta$ & $95 \% \mathrm{Cl}$ & & \\
\hline Model 1 & 0.551 & $0.492,0.611$ & - & - & - & - & 5.675 & $3.832,7.518$ & 0.67 & 1.50 \\
\hline Model 2 & 0.351 & $0.269,0.433$ & 0.177 & $0.121,0.232$ & - & - & 4.573 & $2 \cdot 902,6.245$ & 0.76 & 1.34 \\
\hline \multirow[t]{3}{*}{ Model 3} & 0.356 & $0.274,0.437$ & 0.180 & $0.125,0.236$ & -0.031 & $-0.074,0.011$ & 4.905 & $3 \cdot 180,6 \cdot 629$ & 0.76 & 1.33 \\
\hline & \multicolumn{2}{|c|}{ Height ${ }^{2} / R_{50}\left(\mathrm{~cm}^{2} / \Omega\right)$} & \multicolumn{2}{|c|}{ Weight (kg) } & \multicolumn{2}{|c|}{ Age (years) } & \multicolumn{2}{|c|}{ Intercept (kg) } & & \\
\hline & $\beta$ & $95 \% \mathrm{Cl}$ & $\beta$ & $95 \% \mathrm{Cl}$ & $\beta$ & $95 \% \mathrm{Cl}$ & $\beta$ & $95 \% \mathrm{Cl}$ & & \\
\hline Model 1 & 0.566 & $0.487,0.645$ & - & - & - & - & 5.779 & $3.401,8 \cdot 156$ & 0.71 & 1.49 \\
\hline Model 2 & 0.349 & $0.240,0.458$ & 0.190 & $0.117,0.263$ & - & - & $4 \cdot 297$ & $2 \cdot 149,6 \cdot 444$ & 0.78 & $1 \cdot 30$ \\
\hline Model 3 & 0.351 & $0.241,0.461$ & 0.191 & $0.117,0.266$ & -0.009 & $-0.069,0.051$ & 4.360 & $2 \cdot 157,6.563$ & 0.78 & $1 \cdot 31$ \\
\hline
\end{tabular}

Adj, adjusted; RMSE, root mean square error.

This gives a $95 \%$ limit of agreement (mean $\pm 2 \mathrm{sD}$ ) of -2.64 to $2.68 \mathrm{~kg}$ for predicted relative to actual TBW by impedance and -2.56 to $2.56 \mathrm{~kg}$ for TBW for resistance; that is, for $95 \%$ of women with a resistance measure, predicted measures were within $2.56 \mathrm{~kg}$ of actual measures of TBW. Among just the eighty-two women for whom both resistance and impedance were measured, predicted TBW using the equation for $Z_{50}$ was 0.01 (SD 1.28) $\mathrm{kg}$ lower than actual TBW, with a $95 \%$ limit of agreement of -2.52 to $2.50 \mathrm{~kg}$ between predicted and actual TBW, and TBW predicted from $Z_{50}$ and $R_{50}$ were similar (mean difference of -0.01 (SD 0.17$) \mathrm{kg}, P=0.71)$.

The correlation coefficient in TBW determined via ${ }^{2} \mathrm{H}_{2} \mathrm{O}$ dilution and BIA using $Z_{50}$ was $0.87(P<0.001)$ and using $R_{50}$ was $0.89(P<0.001)$. There was some over-prediction of TBW at the low end and under-prediction at the upper end of the distribution of actual TBW using both impedance and resistance measures, as reflected in the plots of actual $v$. predicted TBW (Figs. 1 and 2).

Using the internal cross-validation approach, prediction residuals were within $4.0 \mathrm{~kg}$ of predicted TBW for both equations, demonstrating individual variability in the ability of the equations to accurately predict TBW (Figs. 3 and 4). The extent of this variability did not differ across the range of predicted TBW. The largest predicted residuals were negative, consistent with an overestimation of TBW using the derived prediction equation in some women compared to their actual TBW. The PRESS statistic (square root of the sum of squared prediction residuals divided by $n$ ) for impedance was $1.35 \mathrm{~kg}$, while that for resistance was $1.33 \mathrm{~kg}$.

Body composition parameters in the wider population using the prediction equation are shown in Table 5. Values across the entire population were similar to those observed among the body composition study participants. One woman whose resistance value was $418 \Omega$, near the cutoff for exclusion as an outlier, had a negative value for fat mass, consistent with a slight over-prediction of TBW, and thus FFM, and subsequent under-prediction of fat mass at the low extreme of the available data.

Associations of body composition measures with age and BMI are also explored in Table 5. Measures of height ${ }^{2} / R_{50}$, TBW (kg) and FFM (kg) were lowest in the youngest women $(P<0.01$ for ANOVA). Expressed as percentage of total body weight, TBW (\%) and FFM (\%) were lower in women 20-30 years of age compared to those over 30 years ( $P=0.008$ for ANOVA), while body fat was highest in 20-30year-old women whether expressed as mass or percentage of total body weight. While TBW (kg), FFM (kg) and fat mass $(\mathrm{kg})$ increased with increasing BMI, the percentage of body fat relative to total body weight increased with increasing BMI while the percentage of body FFM declined.

Table 4. Comparability of body composition measures using ${ }^{2} \mathrm{H}_{2}$ dilution and newly derived prediction equations based on impedance or resistance

(Mean values and standard deviations)

\begin{tabular}{|c|c|c|c|c|c|c|c|c|}
\hline & \multicolumn{4}{|c|}{ Body composition study participants ( $n$ 147) } & \multicolumn{4}{|c|}{ Resistance measurement subgroup ( $n$ 82) } \\
\hline & \multicolumn{2}{|c|}{${ }^{2} \mathrm{H}_{2} \mathrm{O}$ dilution } & \multicolumn{2}{|c|}{$\begin{array}{l}\text { Height }^{2} / Z_{50} \\
\text { prediction }\end{array}$} & \multicolumn{2}{|c|}{${ }^{2} \mathrm{H}_{2} \mathrm{O}$ dilution } & \multicolumn{2}{|c|}{$\begin{array}{l}\text { Height }^{2} / R_{50} \\
\text { prediction }\end{array}$} \\
\hline & Mean & SD & Mean & SD & Mean & SD & Mean & SD \\
\hline Total body water $(\mathrm{kg})$ & $22 \cdot 6$ & $2 \cdot 7$ & $22 \cdot 6$ & $2 \cdot 4$ & $22 \cdot 6$ & $2 \cdot 8$ & $22 \cdot 6$ & 2.5 \\
\hline Total body water (\%) & $55 \cdot 4$ & $4 \cdot 7$ & $55 \cdot 5$ & 3.5 & $54 \cdot 5$ & $4 \cdot 3$ & $54 \cdot 5$ & $3 \cdot 1$ \\
\hline Fat-free mass $(\mathrm{kg})$ & 30.9 & $3 \cdot 7$ & 30.9 & $3 \cdot 3$ & $30 \cdot 8$ & 3.8 & $30 \cdot 8$ & 3.4 \\
\hline Fat-free mass (\%) & $75 \cdot 7$ & $6 \cdot 4$ & $75 \cdot 8$ & 4.7 & 74.4 & 5.9 & 74.4 & 4.3 \\
\hline Fat mass $(\mathrm{kg})$ & $10 \cdot 2$ & $3 \cdot 8$ & $10 \cdot 2$ & 3.4 & $10 \cdot 8$ & 3.7 & $10 \cdot 8$ & $3 \cdot 3$ \\
\hline Fat mass (\%) & $24 \cdot 3$ & 6.4 & 24.2 & 4.7 & $25 \cdot 6$ & 5.9 & $25 \cdot 6$ & $4 \cdot 3$ \\
\hline
\end{tabular}

$Z_{50}$, impedance at $50 \mathrm{kHz} ; R_{50}$, resistance at $50 \mathrm{kHz}$. 


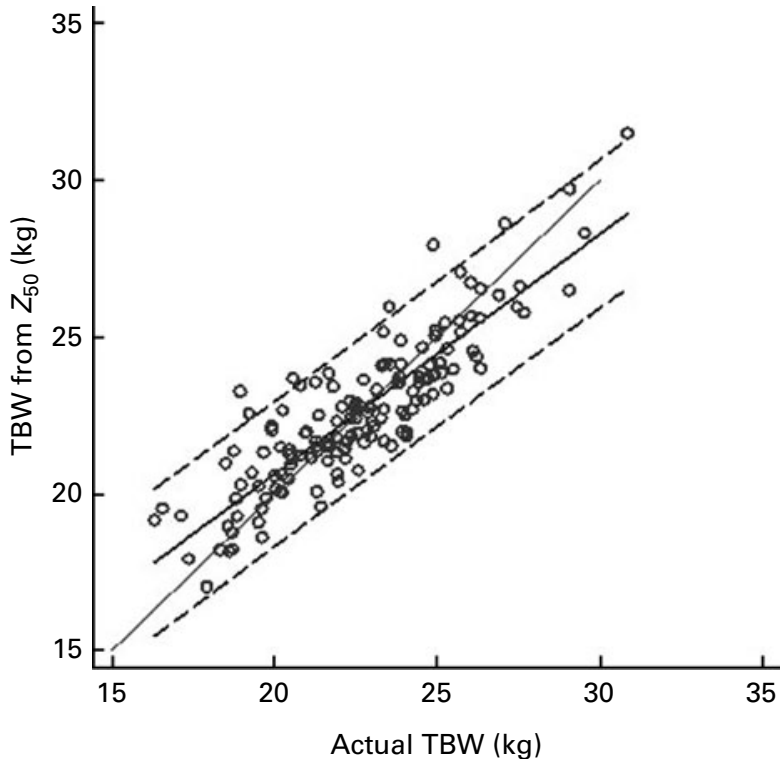

Fig. 1. Scatterplot of the association of total body water (TBW, $\mathrm{kg}$ ) predicted from impedance $\left(Z_{50}\right)$ using equation 1 with actual TBW $(\mathrm{kg})$ obtained from ${ }^{2} \mathrm{H}_{2} \mathrm{O}$ dilution. The dark line in the centre represents the predicted fit, with the dashed lines indicating the $\mathrm{Cl}$ for the forecast values at the $95 \%$ confidence level. The thin grey line indicates the line of identity. Correlation between calculated and actual TBW is $0.87(P<0.0001)$

\section{Discussion}

The purpose of the present study was to develop prediction equations for body composition in rural South Asian women using bioelectrical properties of impedance and resistance to predict TBW assessed using ${ }^{2} \mathrm{H}_{2} \mathrm{O}$ dilution. We selected postpartum women from a large, community-based trial designed to examine pregnancy outcomes in whom to derive these

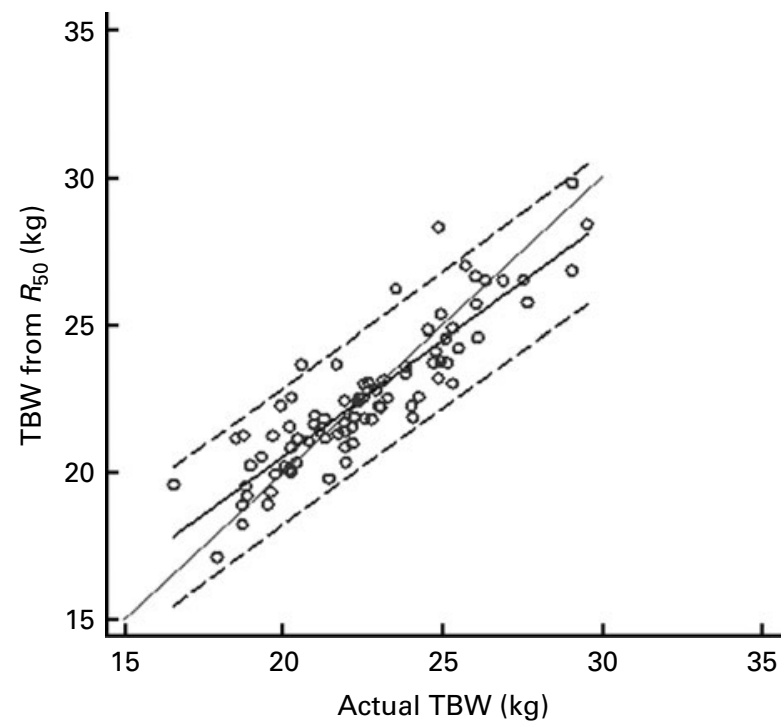

Fig. 2. Scatterplot of the association of total body water (TBW, $\mathrm{kg}$ ), predicted from resistance $\left(R_{50}\right)$ using equation 2 with actual TBW $(\mathrm{kg})$ obtained from ${ }^{2} \mathrm{H}_{2} \mathrm{O}$ dilution. The dark line in the centre represents the predicted fit, with the dashed lines indicating the $\mathrm{Cl}$ for the forecast values at the $95 \%$ confidence level. The thin grey line indicates the line of identity. Correlation between calculated and actual TBW is $0.89(P<0.0001)$. equations. Body composition measures in these women will allow us to more fully explore the facets of nutritional status associated with pregnancy outcomes. Moreover, women in this study were typical of women of reproductive age in the area, who are generally undernourished as determined by weight, height, skinfolds and arm circumference. Thus, we expect these prediction equations to be broadly applicable for describing distributions of body composition parameters among women of reproductive age in the region.

We previously demonstrated the unique bioelectrical characteristics of this population, with the distribution of resistance shifted to higher values than those of women reported elsewhere, and we speculated that this shift was explained by lower body volumes of these undernourished women, estimated from their low heights and weights ${ }^{(17)}$. Among women in the body composition study, impedance and resistance were strongly correlated and had a similar range of values, but on average somewhat lower (14 $\Omega$ ) values were observed for impedance. The close association of these measures was expected, as impedance is related to resistance and reactance by phase angle ${ }^{(11)}$ but comprised primarily (approximately 95\%) of resistance ${ }^{(27)}$. The somewhat lower mean values for impedance compared to resistance observed in this study were probably attributable to the differences in equipment and electrodes used. Nonetheless, while distinct prediction equations were generated for resistance and impedance, the $95 \%$ CI around the $\beta$ coefficients for each variable were overlapping, in agreement with the overall similarity of resistance and impedance across this group of women.

Both prediction equations provided excellent agreement with direct measures of TBW, and estimated TBW and its variance were nearly identical when compared between the eighty-two women in whom equations for impedance and resistance could both be applied. Moreover, both equations demonstrated a high $R^{2}$ and low RMSE as measures of fit and relatively low PRESS statistics in the cross-validation approach. Although there are no specific criteria against

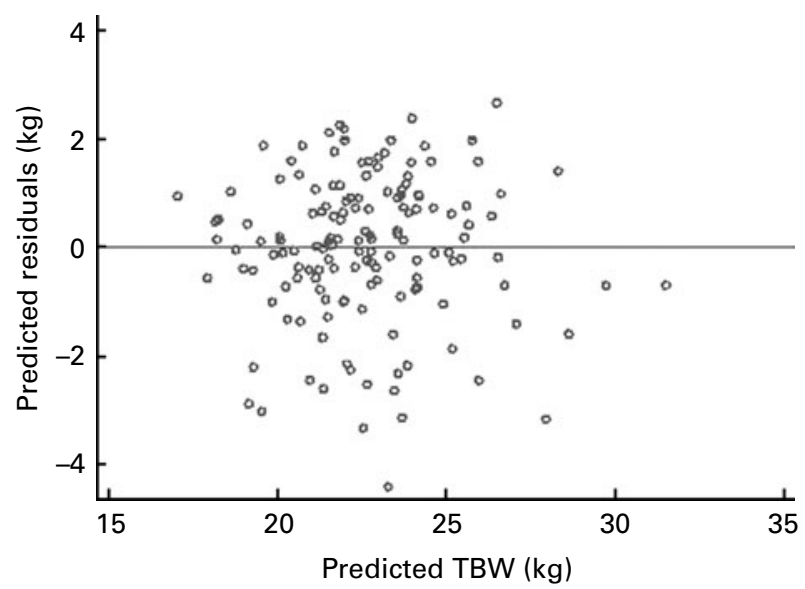

Fig. 3. Plot of prediction residuals (observed total body water (TBW) predicted TBW, where predicted TBW is derived from a regression equation that excludes each observation once) $v$. corresponding predicted TBW $(\mathrm{kg})$ for the prediction equation using impedance at $50 \mathrm{kHz}\left(Z_{50}\right)$. 


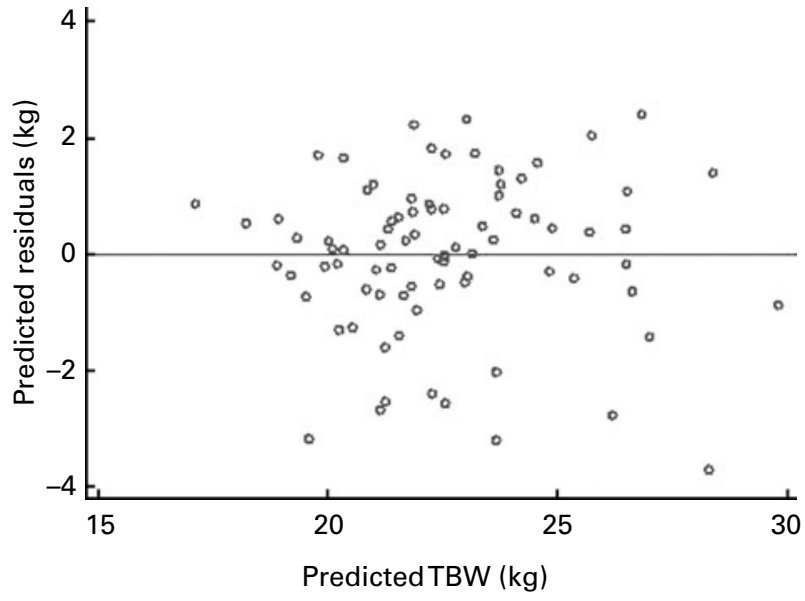

Fig. 4. Plot of prediction residuals (observed total body water (TBW) predicted TBW, where predicted TBW is derived from a regression equation that excludes each observation once) $v$. corresponding predicted TBW $(\mathrm{kg})$ for the prediction equation using resistance at $50 \mathrm{kHz}\left(R_{50}\right)$.

which to evaluate these statistics ${ }^{(25)}$, Sun et al. ${ }^{(26)}$ reported an $R^{2}$ of 0.79 , but a RMSE and PRESS statistic of 2.6 litres, and range of PRESS residuals of about \pm 9 litres in women in the US population in whom prediction equations were generated, although greater homogeneity in the US than Bangladeshi population may have contributed to higher RMSE and PRESS statistics in the US compared to Bangladeshi setting. Individual variability in the ability of the new equations to predict TBW was consistent across the TBW distribution of this population. Although bias in the measures for TBW was low using the new prediction equations, BIA somewhat overestimated actual TBW at the low end and underestimated TBW at the high end of its distribution, explaining lower standard deviations for distributions of body composition measures when assessed by BIA compared to ${ }^{2} \mathrm{H}_{2} \mathrm{O}$ dilution. Thus, despite favourable performance characteristics of these equations overall, users must be mindful of the degree of error surrounding the use of the equations to predict TBW of individuals.
Nonetheless, we demonstrated the utility of these equations for women in this population-based study, in whom body composition information is of great importance to enrich our knowledge of nutritional status. When the prediction equation using resistance was applied to the larger group of postpartum women, FFM comprised approximately $76 \%$ and fat mass $24 \%$ of body weight, similar to the body composition group despite some differences in age and anthropometry between the women selected and those not selected for the body composition study. Among the larger group of women, the highest fat mass and percentage body fat occurred among 20-30year-old women. A tendency towards the highest fat mass in the 20-30-year-old age group is consistent with baseline characteristics that showed greater mean age and higher weight, skinfolds and arm circumference among the women who did not participate in the body composition study compared to typically younger women who did. The lowest total FFM was observed among the youngest study participants, consistent with a hypothesis that these youngest women may have still been acquiring lean body mass at the time they became pregnant ${ }^{(17)}$. A previous study of married adolescents in this population using triceps and subscapular skinfolds to derive percentage body fat showed that body fat was approximately $19 \%$ of body weight, declining by $1.4 \%$ at 6 months postpartum among young women who became pregnant ${ }^{(28)}$. Other studies of body composition in women of reproductive age have shown percentage body fat to average over $30 \%$ among women of Asian descent ${ }^{(12,15,29,30)}$, although mean BMI in those studies typically averaged over $22 \mathrm{~kg} / \mathrm{m}^{2}$. One study in lactating women from India showed persistently low body fat across lactation (6-month intervals to 18 months postpartum) of approximately $28 \%$ body fat $^{(31)}$. It is clear that women in the area of Bangladesh under study here have considerably lower fat mass than women of reproductive age elsewhere worldwide.

Regardless of age, data relating body composition components to BMI show that TBW, FFM and fat mass all increase

Table 5. Application of the height ${ }^{2} /$ resistance at $50 \mathrm{kHz}\left(R_{50}\right)$ prediction equation for body composition to the postpartum women not selected for the body composition study

(Mean values and standard deviations)

\begin{tabular}{|c|c|c|c|c|c|c|c|c|c|c|c|c|c|c|c|c|}
\hline \multirow{4}{*}{$n \ldots$} & & & \multicolumn{6}{|c|}{ Age (years) ${ }^{*}$} & \multicolumn{8}{|c|}{$\mathrm{BMI}\left(\mathrm{kg} / \mathrm{m}^{2}\right) \dagger$} \\
\hline & \multicolumn{2}{|c|}{ All } & \multicolumn{2}{|c|}{$<20$} & \multicolumn{2}{|c|}{$20-30$} & \multicolumn{2}{|c|}{$>30$} & \multicolumn{2}{|c|}{$<18$} & \multicolumn{2}{|c|}{$18-<19$} & \multicolumn{2}{|c|}{$19-<20$} & \multicolumn{2}{|c|}{$\geq 20$} \\
\hline & \multicolumn{2}{|c|}{1020} & \multicolumn{2}{|c|}{367} & \multicolumn{2}{|c|}{547} & \multicolumn{2}{|c|}{105} & \multicolumn{2}{|c|}{287} & \multicolumn{2}{|c|}{221} & \multicolumn{2}{|c|}{206} & \multicolumn{2}{|c|}{306} \\
\hline & Mean & SD & Mean & SD & Mean & SD & Mean & SD & Mean & SD & Mean & SD & Mean & SD & Mean & SD \\
\hline Height $^{2} / R_{50}$ & 32.5 & 4.6 & $31 \cdot 7$ & 4.6 & 32.9 & 4.5 & $33 \cdot 6$ & 4.9 & $30 \cdot 4$ & $3 \cdot 8$ & $32 \cdot 0$ & $4 \cdot 1$ & 32.9 & $4 \cdot 0$ & 34.7 & $5 \cdot 2$ \\
\hline TBW (kg) & $23 \cdot 8$ & $2 \cdot 4$ & $23 \cdot 3$ & $2 \cdot 3$ & $24 \cdot 0$ & $2 \cdot 4$ & 24.2 & 2.5 & $22 \cdot 2$ & $1 \cdot 7$ & $23 \cdot 2$ & 1.8 & 24.0 & 1.9 & $25 \cdot 6$ & 2.5 \\
\hline TBW (\%) & $55 \cdot 8$ & 3.6 & $56 \cdot 0$ & $3 \cdot 2$ & $55 \cdot 6$ & 3.7 & $56 \cdot 7$ & $3 \cdot 8$ & $58 \cdot 1$ & 3.0 & $56 \cdot 7$ & $3 \cdot 0$ & $55 \cdot 6$ & $2 \cdot 6$ & $53 \cdot 2$ & $3 \cdot 2$ \\
\hline FFM (kg) & 32.5 & $3 \cdot 3$ & $31 \cdot 8$ & $3 \cdot 1$ & $32 \cdot 8$ & $3 \cdot 3$ & $33 \cdot 0$ & 3.4 & $30 \cdot 3$ & $2 \cdot 4$ & $31 \cdot 8$ & $2 \cdot 4$ & $32 \cdot 8$ & $2 \cdot 5$ & 34.9 & 3.5 \\
\hline FFM (\%) & $76 \cdot 3$ & 4.9 & 76.5 & 4.5 & 75.9 & $5 \cdot 0$ & 77.5 & $5 \cdot 2$ & $79 \cdot 4$ & $4 \cdot 1$ & 77.5 & $4 \cdot 1$ & $76 \cdot 0$ & 3.5 & $72 \cdot 6$ & 4.3 \\
\hline Fat (kg) & $10 \cdot 3$ & 3.2 & 9.9 & $2 \cdot 6$ & $10 \cdot 7$ & 3.4 & $9 \cdot 8$ & $3 \cdot 2$ & 7.9 & 1.9 & $9 \cdot 3$ & 1.9 & $10 \cdot 4$ & 1.9 & $13 \cdot 3$ & $3 \cdot 1$ \\
\hline Fat (\%) & $23 \cdot 7$ & 4.9 & 23.5 & 4.5 & $24 \cdot 1$ & 5.0 & 22.5 & $5 \cdot 2$ & $20 \cdot 6$ & $4 \cdot 1$ & $22 \cdot 5$ & $4 \cdot 1$ & 24.0 & 3.5 & $27 \cdot 4$ & 4.3 \\
\hline
\end{tabular}

TBW, total body water; FFM, fat-free mass.

${ }^{*}$ Age group differences all significant by ANOVA, $P<0.0001$, except TBW (\%) and FFM (\%), $P=0.008$; fat $(\mathrm{kg}), P=0.0006$; for multiple comparison tests of height ${ }^{2} / R_{50}$, TBW $(\mathrm{kg})$, FFM $(\mathrm{kg})$, women $<20$ differ from women $20-30$ and $>30$ years; for TBW (\%), FFM (\%), fat $(\%)$, women $20-30$ differ from women $>30$ years; for fat $(\mathrm{kg})$, women 20-30 differ from women $<20$ and $>30$ years, $P<0.05$.

$\dagger \mathrm{BMI}$ group differences all significant by ANOVA $(P<0.0001)$. 
with increasing BMI. However, when expressed as a percentage of total body weight, only percentage body fat increased with increasing BMI. These findings demonstrate that BMI reflects body fat across the range of BMI observed in this study, extending findings in other studies that relate body fat to BMI to the low end of the BMI distribution ${ }^{(32-34)}$.

For our calculations, we assumed a hydration constant for FFM of 0.732 among all women. The accuracy of estimates of FFM and fat mass depend on the accuracy of that constant, which in reality may vary from 0.70 to 0.76 , and may differ by individual and in relation to body fat ${ }^{(24,30)}$, a limitation of the two-compartment approach for assessing body composition $^{(35)}$. The hydration of FFM increases during pregnancy, to an estimated 0.76 in the third trimester, before declining in the postpartum period. At 2 weeks postpartum, Hopkinson et $a{ }^{(36)}$ reported a hydration constant of 0.75 , and Butte et $a l .{ }^{(37)}$ reported that hydration of FFM had returned to prepregnancy values by 3 months postpartum in a relatively small group of American women. It is reasonable to assume that hydration of FFM had returned to pre-pregnancy values by 3 months postpartum in our study participants, particularly given that resistance measures across an entire reproductive cycle returned to early pregnancy (assumed to be close to non-pregnancy) values by 3 months postpartum in this population $^{(17)}$. If, however, the true hydration of FFM was higher among women assessed at the 3-month postpartum home visit compared to women of the body composition study who were assessed somewhat later postpartum, estimates of TBW would still be valid, but FFM would be somewhat overestimated and fat mass underestimated in the larger population relative to the body composition study group. Nonetheless, because the equations are valid for predicting TBW, we believe the equations derived here can be generally applied for population studies of body composition among women of reproductive age in this region, with the caveat that ideally the potential variability in hydration of the FFM compartment should be better understood.

In conclusion, the present study provided new equations for measuring TBW based on resistance or impedance, height and weight. BIA is simple, rapid and accurate for South Asian rural women and can be a useful tool for determining body composition in nutritional surveys in field studies. Future studies will allow us to examine associations of body composition with birth outcomes for mother and child in this population. Moreover, because this population remains under surveillance, future work may also allow us to link body composition to other health outcomes among women in this setting.

\section{Acknowledgements}

Support for the present work was provided by the International Atomic Energy Agency, Vienna, Austria; Bill and Melinda Gates Foundation, Seattle, WA, USA (grant no. 614 Global Control of Micronutrient Deficiency); US Agency for International Development (Washington, DC, USA; Global Research Activity GHSA-00-03-00019-00); Sight and Life Research Institute, Baltimore, MD, USA. This study was conducted under an agreement with the National Integrated Population and Health Program of the Ministry of Health and Family Welfare of the Government of the People's Republic of Bangladesh. The authors' contributions to the study were as follows: S. S. provided scientific oversight, operationalised the study, analysed the data and drafted the manuscript; K. J. S. engaged in study design, analysis and manuscript preparation; A. K. completed the ${ }^{2} \mathrm{H}_{2} \mathrm{O}$ assessments; $\mathrm{H}$. A. oversaw field operations, subject recruitment and participation; A. A. S. and M. R. provided scientific and administrative oversight of the main trial and its intersection with this study; S. M. assisted with manuscript preparation and study organisation and management; L. S.-F. W. managed all trial data and supported the data analysis; A. B. L., as project scientist for the main trial, coordinated activities with IAEA and within Bangladesh and oversaw the study design; P. C. and K. P. W. were the principal investigators for the main trial and provided guidance throughout the research process. None of the authors has conflicts of interest to declare. The contributions of the JiVitA field and data management teams, Johns Hopkins collaborators, and the staff at Saint Johns Research Institute are gratefully acknowledged.

\section{References}

1. Lawn JE, Cousens S \& Zupan J (2005) 4 Million neonatal deaths: when? where? why? Lancet 365, 891-900.

2. Christian P, West KP, Khatry SK, et al. (2003) Effects of maternal micronutrient supplementation on fetal loss and infant mortality: a cluster-randomized trial in Nepal. Am J Clin Nutr 78, 1194-1202.

3. Jiang T, Christian P, Khatry SK, et al. (2005) Micronutrient deficiencies in early pregnancy are common, concurrent, and vary by season among rural Nepali pregnant women. J Nutr 135, 1106-1112.

4. Ronnenberg AG, Wang X, Xing H, et al. (2003) Low preconception body mass index is associated with birth outcome in a prospective cohort of Chinese women. J Nutr 133, 3449-3455.

5. Kulkarni B, Shatrugna V \& Balakrishna N (2006) Maternal lean body mass may be the major determinant of birth weight: a study from India. Eur J Clin Nutr 60, 1341-1344.

6. Sanin Aguirre LH, Reza-Lopez S \& Levario-Carrillo M (2004) Relation between maternal body composition and birth weight. Biol Neonate 86, 55-62.

7. Misra A, Pandey RM, Devi JR, et al. (2001) High prevalence of diabetes, obesity and dyslipidaemia in urban slum population in northern India. Int J Obes Relat Metab Disord 25, $1722-1729$

8. Wang J, Thornton JC, Russell M, et al. (1994) Asians have lower body mass index (BMI) but higher percent body fat than do Whites: comparisons of anthropometric measurements. Am J Clin Nutr 60, 23-28.

9. WHO Expert Consultation (2004) Appropriate body-mass index for Asian populations and its implications for policy and intervention strategies. Lancet 363, 157-163.

10. Deurenberg P, Deurenberg-Yap M \& Guricci S (2002) Asians are different from Caucasians and from each other in their body mass index/body fat per cent relationship. Obes Rev 3, 141-146.

11. Kyle UG, Bosaeus I, De Lorenzo AD, et al. (2004) Bioelectrical impedance analysis - part I: review of principles and methods. Clin Nutr 23, 1226-1243. 
12. Deurenberg P, Deurenberg-Yap M \& Schouten FJ (2002) Validity of total and segmental impedance measurements for prediction of body composition across ethnic population groups. Eur J Clin Nutr 56, 214-220.

13. Deurenberg P \& Deurenberg-Yap M (2002) Validation of skinfold thickness and hand-held impedance measurements for estimation of body fat percentage among Singaporean Chinese, Malay and Indian subjects. Asia Pac J Clin Nutr 11, 1-7.

14. Deurenberg P, van der Kooy K, Leenen R, et al. (1991) Sex and age specific prediction formulas for estimating body composition from bioelectrical impedance: a cross-validation study. Int J Obes 15, 17-25.

15. Rush EC, Chandu V \& Plank LD (2006) Prediction of fat-free mass by bioimpedance analysis in migrant Asian Indian men and women: a cross validation study. Int J Obes (Lond) 30, $1125-1131$.

16. Kuriyan R, Petracchi C, Ferro-Luzzi A, et al. (1998) Validation of expedient methods for measuring body composition in Indian adults. Indian J Med Res 107, 37-45.

17. Shaikh S, Schulze KJ, Ali H, et al. (2011) Bioelectrical impedance among rural Bangladeshi women during pregnancy and in the postpartum period. J Health Popul Nutr 29, 236-244.

18. West KP Jr, Christian P, Labrique AB, et al. (2011) Effects of vitamin A or beta-carotene supplementation on pregnancyrelated mortality and infant mortality in rural Bangladesh: a cluster randomized trial. JAMA 305, 1986-1995.

19. Labrique AB, Christian P, Klemm RD, et al. (2011) A clusterrandomized, placebo-controlled, maternal vitamin A or betacarotene supplementation trial in Bangladesh: design and methods. Trials 12, 102.

20. Powers ME, Arnold BL, Weltman AL, et al. (2003) Creatine supplementation increases total body water without altering fluid distribution. J Athl Train 38, 44-50.

21. International Atomic Energy Agency (1990) The Doubly Labelled Water Method for Measuring Energy Expenditure: Technical Recommendation for Use in Humans. A Consensus Report by the IDECG Working Group [AM Prentice, editor]. Vienna: International Atomic Energy Agency.

22. Schoeller DA \& Jones PJH (1987) Measurement of total body water by isotope dilution: a unified approach to calculations. In In Vivo Body Composition Studies, pp. 131-137 [K Ellis, $S$ Yasamura and WD Morgan, editors]. London: Institute of Physical Sciences in Medicine.

23. Wang Z, Deurenberg P, Wang W, et al. (1999) Hydration of fat-free body mass: new physiological modeling approach. Am J Physiol 276, E995-E1003.

24. Wang Z, Deurenberg P, Wang W, et al. (1999) Hydration of fat-free body mass: review and critique of a classic body-composition constant. Am J Clin Nutr 69, 833-841.
25. Guo SS, Chumlea WC \& Cockram DB (1996) Use of statistical methods to estimate body composition. Am J Clin Nutr 64 , 428S-435S.

26. Sun SS, Chumlea WC, Heymsfield SB, et al. (2003) Development of bioelectrical impedance analysis prediction equations for body composition with the use of a multicomponent model for use in epidemiologic surveys. Am J Clin Nutr 77, 331-340.

27. Buffa R, Floris G \& Marini E (2002) Bioelectrical impedance vector in pre- and postmenarcheal females. Nutrition 18, 474-478.

28. Rah JH, Christian P, Shamim AA, et al. (2008) Pregnancy and lactation hinder growth and nutritional status of adolescent girls in rural Bangladesh. J Nutr 138, 1505-1511.

29. Kulkarni B, Shatrugna V, Nagalla B, et al. (2010) Regional body composition of Indian women from a low-income group and its association with anthropometric indices and reproductive events. Ann Nutr Metab 56, 182-189.

30. Deurenberg-Yap M, Schmidt G, van Staveren WA, et al. (2001) Body fat measurement among Singaporean Chinese, Malays and Indians: a comparative study using a fourcompartment model and different two-compartment models. Br J Nutr 85, 491-498.

31. Kulkarni B, Shatrugna V, Nagalla B, et al. (2011) Regional body composition changes during lactation in Indian women from the low-income group and their relationship to the growth of their infants. J Am Coll Nutr 30, 57-62.

32. Gallagher D, Visser M, Sepulveda D, et al. (1996) How useful is body mass index for comparison of body fatness across age, sex, and ethnic groups? Am J Epidemiol 143, 228-239.

33. Gallagher D, Heymsfield SB, Heo M, et al. (2000) Healthy percentage body fat ranges: an approach for developing guidelines based on body mass index. Am J Clin Nutr $\mathbf{7 2}$, 694-701.

34. Meeuwsen S, Horgan GW \& Elia M (2010) The relationship between BMI and percent body fat, measured by bioelectrical impedance, in a large adult sample is curvilinear and influenced by age and sex. Clin Nutr 29, 560-566.

35. Wang ZM, Pierson RN Jr \& Heymsfield SB (1992) The five-level model: a new approach to organizing bodycomposition research. Am J Clin Nutr 56, 19-28.

36. Hopkinson JM, Butte NF, Ellis KJ, et al. (1997) Body fat estimation in late pregnancy and early postpartum: comparison of two-, three-, and four-component models. $\mathrm{Am} \mathrm{J}$ Clin Nutr 65, 432-438.

37. Butte NF, Hopkinson JM, Ellis KJ, et al. (1997) Changes in fat-free mass and fat mass in postpartum women: a comparison of body composition models. Int $J$ Obes Relat Metab Disord 21, 874-880. 